\title{
Tungiasis, una enfermedad tropical emergente en Chile. Comunicación de tres casos clínicos importados
}

\author{
Félix Fich, Pablo Del Barrio-Díaz, Sandra Kam, Vilma Celle, \\ Marcela Concha, Marianne Kolbach y Juan E. Carrasco-Zuber
}

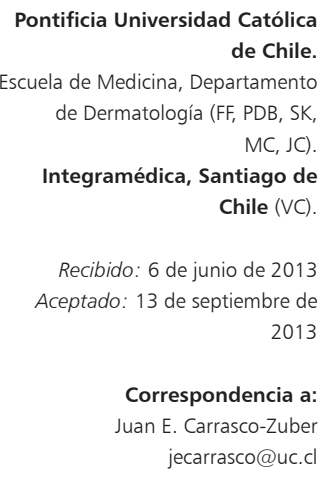

Correspondencia a: jecarrasco@uc.c

\section{Tungiasis, an emerging tropical disease in Chile. Three imported cases reports}

Tungiasis is a cutaneous ectoparasitosis caused by the sand flea Tunga penetrans whose higher prevalence occurs in South America, the Caribbean and Sub-Saharan Africa. It is clinically characterized by a papular lesion, either single or multiple, with a whitish halo and a brown-black central core, most of them localized on the feet. The lesions can be painful and itchy with the most common complication being bacterial superinfection of the skin. We report three cases of Chilean patients who presented skin lesions suggestive of tungiasis on their return from areas of high prevalence of the disease. The diagnosis is made by the clinical features of lesions in a patient from an endemic zone. Standard treatment consists of surgical extraction of the flea followed by application of a topical antibiotic and a tetanus prophylaxis. Prevention of the infestation is essential and includes the use of closed footwear and repellents.

Key words: Parasites, ectoparasitosis, tunga, tungiasis.

Palabras clave: Parásitos, ectoparasitosis, tunga, tungiasis.

\section{Introducción}

$\mathrm{L}$ a tungiasis es una endozoonosis, originaria de América Central y del Sur, que causa en el ser humano una ectoparasitosis transitoria por la penetración en la piel de la hembra grávida de la pulga de la arena, Tunga penetrans ${ }^{1,2}$. Como consecuencia de la inmigración y del aumento de viajes a destinos tropicales se ha observado un aumento de la incidencia de la tungiasis fuera de las áreas endémicas, lo que constituye un desafío diagnóstico. Por este motivo, consideramos necesario que los médicos estén informados sobre sus manifestaciones clínicas, conducta diagnóstica y terapéutica.

Se presentan tres casos clínicos diagnosticados en nuestro centro.

\section{Casos clínicos}

\section{Caso 1}

Varón de 19 años, previamente sano, consultó 20 días después de regresar de un viaje turístico a Paraguay, por lesiones cutáneas tipo pápulas de coloración amarillo-verdoso de forma circular, de 6-7 mm de diámetro, con centro negruzco, de bordes bien definidos e hiperpigmentados, ubicadas sobre una base levemente eritematosa en la zona subungueal del primer ortejo y planta del pie derecho (Figura 1). La lesión plantar le ocasionaba molestias al deambular. Se procedió a la remoción quirúrgica completa de la lesión (Figura 2). Además se administró profilaxis antimicrobiana y dos dosis de ivermectina separadas por una semana. La evolución del paciente fue satisfactoria.

\section{Caso 2}

Mujer de 20 años, sin antecedentes mórbidos. Consultó por presentar una lesión cutánea dolorosa tipo pápula, pardo-negruzca, de bordes eritematosos, ubicada en el pulpejo del segundo ortejo del pie izquierdo. En la superficie de la lesión se encontró múltiples huevecillos de color blanco, de menos de $1 \mathrm{~mm}$ de diámetro (Figura 3). La paciente había regresado de un viaje turístico a Paraguay 10 días antes. Se realizó la extracción quirúrgica de los parásitos. Además se indicaron antibacterianos tópicos y profilaxis antitetánica, con resolución total de las lesiones.

\section{Caso 3}

Mujer de 33 años, con antecedentes de infección por $\mathrm{VIH}$ en tratamiento antirretroviral, que permaneció en Brasil durante 10 días. Una semana después de su regreso a Chile presentó lesiones cutáneas tipo pápulas pardonegruzcas, pruriginosas y dolorosas a la palpación, de 5-6 mm de diámetro, en la planta del pie izquierdo. A la dermatoscopia se observó un anillo central marrón oscuro, rodeado de un halo blanquecino hiperqueratósico (Figura 4). El tratamiento consistió en la extirpación y curetaje del lecho de las lesiones seguido de crioterapia con nitrógeno 


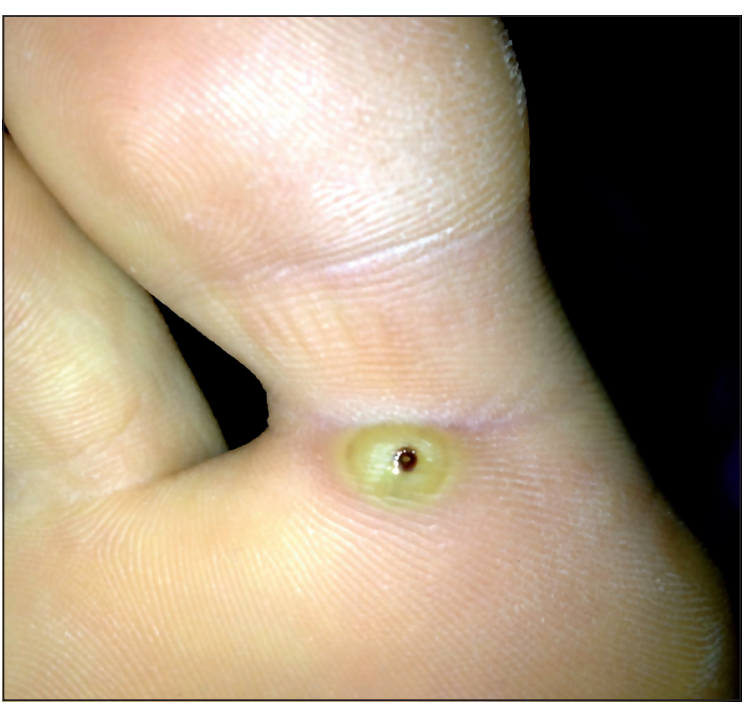

Figura 1. Pápula de coloración amarillo-verdoso y forma circular, de $7 \mathrm{~mm}$ de diámetro, con centro negruzco, de bordes bien definidos e hiperpigmentados, ubicada sobre una base levemente eritematosa en la planta del pie derecho.

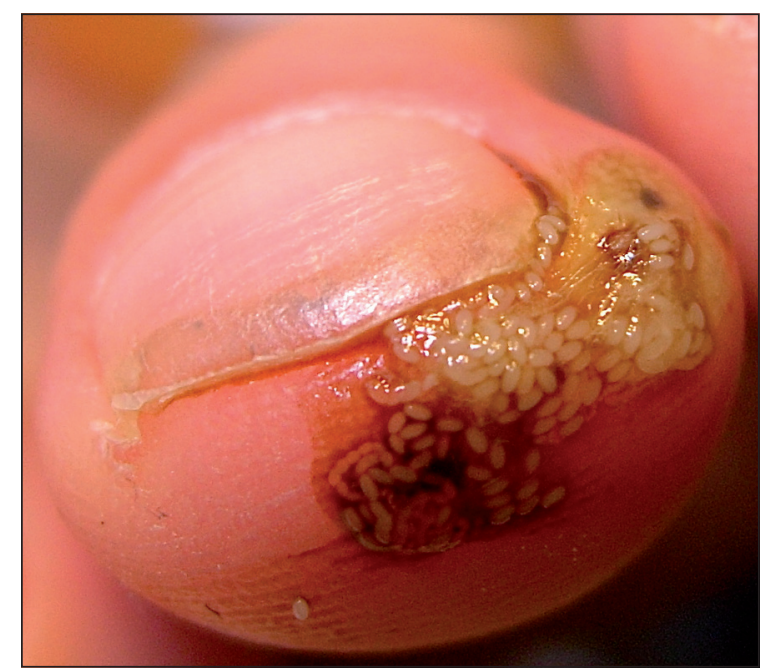

Figura 3. Múltiples huevecillos de color blanco, menores de $1 \mathrm{~mm}$ de diámetro, ubicados en la superficie del pulpejo del segundo ortejo del pie izquierdo.

líquido. La imagen de la pulga, una vez extraída, permitió observar una estructura marrón-amarillenta y algunos huevos blanquecinos en su periferia, compatibles con la presencia del parásito (Figura 5). La paciente evolucionó satisfactoriamente, sin presentar nuevas lesiones.

En los tres casos anteriormente presentados, considerando la morfología y localización de las lesiones asociado al antecedente de viajes a zonas endémicas de tungiasis, el diagnóstico se realizó en forma clínica sin necesidad de recurrir al análisis histopatológico.

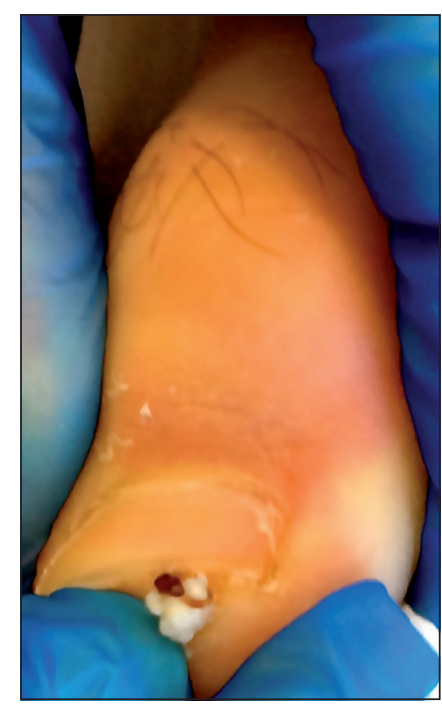

Figura 2. Remoción del parásito ubicado en pulpejo del primer ortejo del pie derecho. A la compresión secreta una sustancia espesa amarillenta.

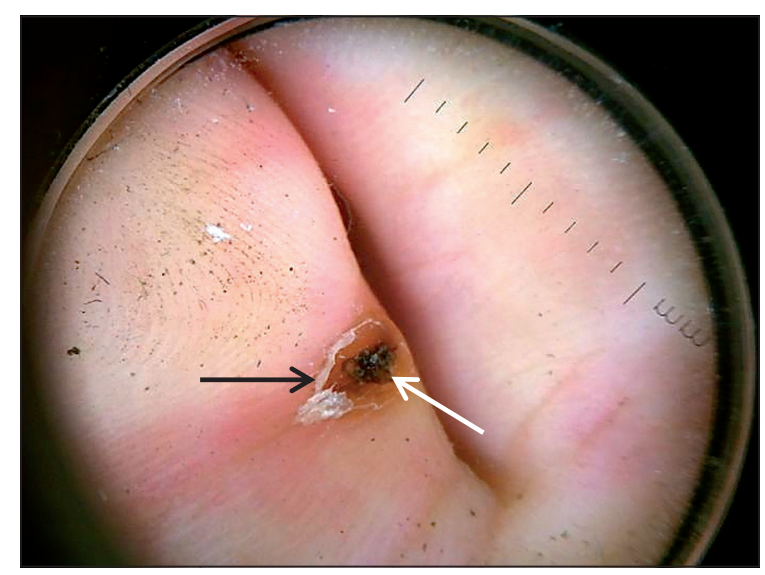

Figura 4. Imagen dermatoscópica de lesión ubicada en la planta del pie izquierdo. Se observa un anillo central marrón oscuro (flecha blanca), rodeado de un halo blanquecino de superficie hiperqueratósica (flecha negra).

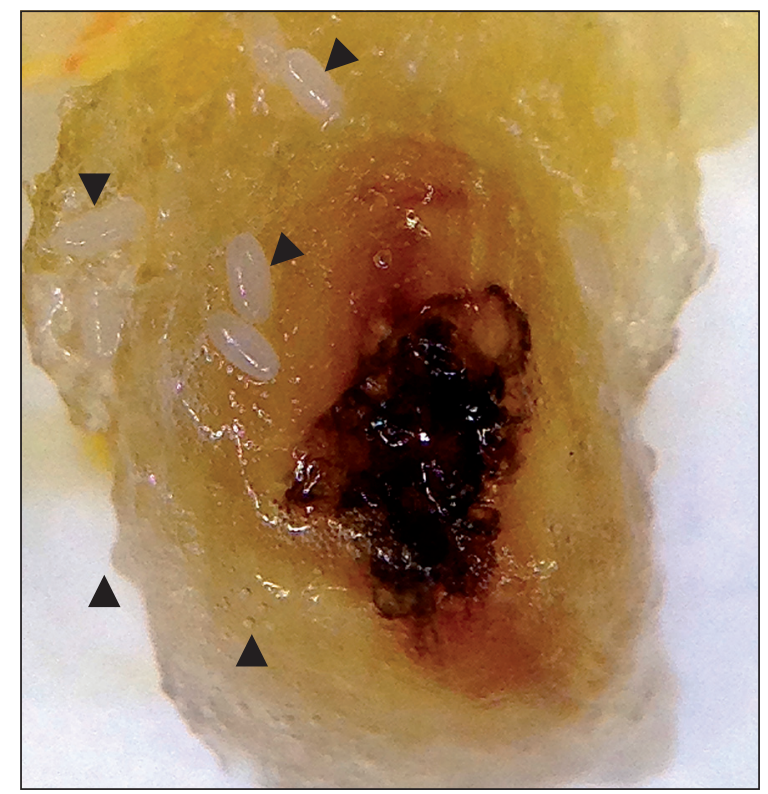

Figura 5. Imagen de la pulga una vez extraída. Se observa una estructura marrónamarillenta y algunos huevos blanquecinos en su periferia (puntas de flechas negras), compatibles con la presencia del parásito. 


\section{Discusión}

La tungiasis corresponde a una ectoparasitosis cutánea causada por la penetración de la pulga hematófaga Tunga penetrans en la epidermis de un hospedero, produciendo lesiones pruriginosas características ${ }^{2}$. Este agente causal se caracteriza por ser la especie de pulga más pequeña conocida, con $1 \mathrm{~mm}$ de longitud y por tener la capacidad de saltar hasta $35 \mathrm{~cm}$ del suelo ${ }^{4}$. Otros nombres por los que se le conoce son: "pulga de arena" en Sudamérica, "nigua" en Centroamérica y "sand flea" en países americanos de habla inglesa. Estudios epidemiológicos confirman que la pulga prevalece en asentamientos humanos urbanos y rurales de Sudamérica, el Caribe y África Subsahariana. En estos lugares es una infestación endémica, constituyendo un grave problema de salud pública ${ }^{4,5}$. En otras áreas del mundo los casos publicados corresponden a turistas afectados que han regresado de un área endémica o inmigrantes que provienen de dichas áreas ${ }^{6}$.

La enfermedad es una zoonosis cuyo huésped principal es el cerdo, siendo el ser humano un hospedero accidental. La infección en el ser humano se ve favorecida por importantes factores socioculturales asociados con la pobreza, la costumbre de caminar descalzo o con sandalias, la falta de higiene y la entrada de animales libremente en las casas como cerdos, perros y ratas ${ }^{7}$. La transmisión de la pulga suele producirse como consecuencia de la deambulación sin calzado sobre suelos contaminados por heces de animales infestados. Debido a que la pulga ejecuta un salto corto, las lesiones se producen en los pies en 95\% de los casos, con predilección por la región plantar, maleolar, periungueal e interdigital ${ }^{4,5}$. En 5 a $10 \%$ restante la pulga T. penetrans afecta cualquier otro sitio corporal. En forma esporádica y habitualmente en niños se ha comunicado el compromiso en otras zonas como manos, codos, muslos, glúteos y párpados. Esto se explica por la menor estatura $\mathrm{y}$, por lo tanto, la mayor capacidad del parásito de alcanzar segmentos corporales superiores ${ }^{8}$. Una vez que la hembra grávida penetra en la epidermis produce cientos de huevos mientras se alimenta de la sangre de su hospedero.

Los signos clínicos de la enfermedad están relacionados con la historia natural de la infestación por el parásito, caracterizándose por la formación de pápulas, nódulos y/o placas, únicos o múltiples, blanquecinos, grisáceos o marrones, que traducen el desarrollo de la pulga y la infección secundaria. Al comienzo la lesión es asintomática, sin embargo, posteriormente puede ser pruriginosa, dolorosa al tacto y, según su ubicación, también al deambular. El diagnóstico se basa en la morfología y localización de las lesiones, incluyendo el antecedente de viajes realizados a zonas endémicas de tungiasis.

En zonas endémicas el diagnóstico se realiza generalmente con el examen clínico, sin necesidad del estudio histopatológico ${ }^{9}$. Se ha empleado la dermatoscopia como una herramienta eficaz, práctica y no invasora para el diagnóstico de tungiasis. Entre las características dermatoscópicas que se describen se encuentra la presencia de un anillo marrón central en torno a un poro, correspondiente a la apertura posterior del exoesqueleto, un halo o anillo pigmentado periférico, que corresponde a la parte posterior del abdomen del parásito y múltiples manchas azul-grisáceas, que traducen el desarrollo de huevos en el abdomen de la pulga ${ }^{10}$. Recientemente se ha descrito el signo de la corona radial; sin embargo, este hallazgo presenta mayor variabilidad y no está presente en todos los $\operatorname{casos}^{11}$. Para las lesiones de ubicación o morfología atípica o casos que afectan a viajeros que regresan desde zonas endémicas la biopsia permite demostrar la presencia del parásito, huevos o fragmentos parasitarios que sugieran el diagnóstico ${ }^{12}$.

Los diagnósticos diferenciales incluyen: escabiosis, piodermitis o abscesos, larva migrans cutánea, miasis, tumores, verrugas, reacción a un cuerpo extraño, entre otras $^{4}$.

El tratamiento de elección es la extracción quirúrgica de la pulga y de las lesiones con técnica estéril. Este procedimiento debe realizarse lo más pronto posible para evitar la sobreinfección bacteriana. Se recomienda ampliar la abertura en la epidermis con una aguja estéril asegurando la extracción completa de la pulga, ya que la persistencia de cualquier resto provocará una reacción inflamatoria intensa. Luego del procedimiento se sugiere aplicar en la herida antibacterianos tópicos, como mupirocina al $2 \%$, dos veces al día, durante siete a diez días. La administración del toxoide tetánico debe indicarse a todos los pacientes no vacunados o aquellos que recibieron la última dosis de vacuna anti-tetánica con anterioridad a cinco años ${ }^{4}$.

Cuando las lesiones son muy numerosas o hay pústulas, puede ser necesario el empleo de antimicrobianos sistémicos ${ }^{13}$. Un ensayo clínico aleatorio (ECA) efectuado en 108 pacientes, demostró que el uso tópico de ivermectina (loción), tiabendazol (ungüento y loción) o metrifonato (loción) tiene cierta eficacia en disminuir el número de lesiones en comparación con placebo ${ }^{14}$. Con respecto al uso de antiparasitarios por vía sistémica, un ECA documentó que el uso de ivermectina no es más efectivo en el tratamiento de la enfermedad comparado con placebo ${ }^{15}$. La complicación más frecuente de esta ectoparasitosis es la sobreinfección bacteriana, principalmente en pacientes donde se manipuló la lesión con instrumentos no estériles. Asimismo, las lesiones pueden ser puerta de entrada de microorganismos como Clostridium tetani en pacientes sin inmunización. Otras complicaciones son la formación de úlceras, linfedema, gangrena y autoamputación de dedos ${ }^{16}$.

La prevención de la infestación es fundamental por lo que se recomienda a los viajeros a zonas endémicas el uso de calzado cerrado, evitar sentarse o recostarse en sitios en que habita la pulga, autoexploración diaria para detectar 


\begin{tabular}{|c|c|c|c|c|c|c|c|}
\hline Cita & Sexo-edad & Nacionalidad & Procedencia & $\mathrm{n}$ de lesiones & Localización & Clínica & Tratamiento \\
\hline $\begin{array}{l}\text { Spronhle y cols. } \\
(1992)^{1}\end{array}$ & $\begin{array}{l}\text { Masculino - } \\
22 \text { años }\end{array}$ & Chilena & Selva Amazónica & Múltiples & $\begin{array}{l}5^{\circ} \text { dedo del pie derecho, } \\
\text { talón del pie izquierdo }\end{array}$ & Dolor, prurito & $\begin{array}{l}\text { Curetaje, antimicrobianos, } \\
\text { profilaxis antitetánica }\end{array}$ \\
\hline $\begin{array}{l}\text { Vergara y cols. } \\
(2009)^{2}\end{array}$ & $\begin{array}{l}\text { Masculino - } \\
23 \text { años }\end{array}$ & Chilena & Brasil & Múltiples & Dedos y plantas de los pies & Dolor, prurito & $\begin{array}{l}\text { Curetaje, profilaxis } \\
\text { antitetánica }\end{array}$ \\
\hline $\begin{array}{l}\text { Tapia y cols. } \\
(2011)^{3}\end{array}$ & $\begin{array}{l}\text { Masculino - } \\
54 \text { años }\end{array}$ & Chilena & Brasil & Única & Dorso de la muñeca & Prurito & $\begin{array}{l}\text { Curetaje, antimicrobianos, } \\
\text { profilaxis antitetánica }\end{array}$ \\
\hline Caso 1 & $\begin{array}{l}\text { Masculino - } \\
19 \text { años }\end{array}$ & Chilena & Paraguay & Dos & $\begin{array}{l}1^{\circ} \text { dedo y planta del pie } \\
\text { derecho }\end{array}$ & Dolor & $\begin{array}{l}\text { Curetaje, antimicrobianos, } \\
\text { ivermectina }\end{array}$ \\
\hline Caso 2 & $\begin{array}{l}\text { Femenino - } \\
20 \text { años }\end{array}$ & Chilena & Paraguay & Única & $2^{\circ}$ dedo del pie izquierdo & Dolor & $\begin{array}{l}\text { Curetaje, antimicrobianos, } \\
\text { profilaxis antitetánica }\end{array}$ \\
\hline Caso 3 & $\begin{array}{l}\text { Femenino - } \\
33 \text { años }\end{array}$ & Chilena & Brasil & Múltiples & Planta del pie izquierdo & Dolor, prurito & Curetaje, crioterapia \\
\hline
\end{tabular}

lesiones incipientes y el uso de repelentes durante todo el tiempo de permanencia en la zona ${ }^{13,15}$.

Hasta la fecha se han publicado en Chile tres casos

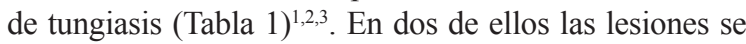
localizaban en los pies (dedos y plantas), mientras que en un caso la lesión se ubicaba en el dorso de la muñeca. La sintomatología predominante era dolor y/o prurito. Los pacientes eran chilenos, sin embargo, en todos los casos existía el antecedente de viaje a zonas endémicas de tungiasis, la mayoría a Brasil. La evolución fue favorable tras tratamiento, al igual que lo observado en nuestros pacientes.

\section{Resumen}

La tungiasis es una ectoparasitosis cutánea causada por la pulga Tunga penetrans, prevalente en Sudamérica, el Caribe y África Subsahariana. Clínicamente se caracteriza por la formación de pápulas, únicas o múltiples, con un halo blanquecino translúcido y una región central pardo-negruzca, frecuentemente localizadas en los pies. Las lesiones pueden cursar con prurito o dolor leve, siendo la sobreinfección bacteriana la complicación más frecuente. Se comunican tres casos clínicos de chilenos que viajaron a zonas de alta prevalencia de tungiasis y que a su regreso presentaron lesiones dérmicas sugerentes de la enfermedad. El diagnóstico se realizó en base a las características clínicas de las lesiones en un paciente proveniente de zonas endémicas. El tratamiento de elección es la extracción quirúrgica de la pulga seguido del uso de antimicrobianos tópicos y la vacunación antitetánica. La prevención es esencial con el uso de calzado cerrado y repelentes.

\section{Referencias bibliográficas}

1.- Spronhle V, Apt W, Eguiguren G, Pérez C, Zulantay I. Tungiasis: caso clínico. Rev Med Chile 1992; 120: 794-6.

2.- Vergara M C, Barthel M E, Labarca M E, Neira O P, Espinoza E R. Tungiasis afecta a un turista chileno. Rev Chilena Infectol 2009; 26: 265-9.

3.- Tapia O, Kam S, Naranjo M, Villaseca M. Tungiasis: una rara ectoparasitosis. Caso clínico. Rev Med Chile 2011; 139: 1206-9.

4.- Heukelbach J. Tungiasis. Rev Inst Med Trop Sao Paulo 2005; 47: 307-13.

5.- Sachse MM, Guldbakke KK, Khachemoune A. Tunga penetrans: a stowaway from around the world. J Eur Acad Dermatol Venereol 2007; 21: 11-6.

6.- Heemskerk J, van Empel I, Jakimowicz J J. Tunga penetrans. A case report and review of the literature. Acta Chir Belg 2005; 105 : 548-50.

7.- Ugbomoiko U S, Ariza L, Ofoezie I E, Heukelbach J. Risk factors for tungiasis in Nigeria: identification of targets for effective intervention. PLoS Negl Trop Dis 2007; 1: e87.

8.- Heukelbach J, Wilcke T, Eisele M, Feldmeier H. Ectopic localization of tungiasis. Am J Trop Med Hyg 2002; 67: 214-6.

9.- Sendagorta E, Vidaurrázaga C, Mulekyo R. Placa hiperpigmentada en el pie de un paciente keniata. Actas Dermosifiliogr 2012; 103: 633-4.

10.- Zalaudek I, Giacomel J, Cabo H, Di Stefani A, Ferrara G, Hofmann- Wellenhof R, et al. Entodermoscopy: a new tool for diagnosing skin infections and infestations. Dermatology 2008; 216: 14-23.

11.- Marazza G, Campanelli A, Kaya G, Braun RP, Saurat JH, Piguet V. Tunga penetrans: description of a new dermoscopic sign-the radial crown. Arch Dermatol 2009; 145: 348-9.

12.- Smith M D, Procop G W. Typical histologic features of Tunga penetrans in skin biopsies. Arch Pathol Lab Med 2002; 126: 714-6.

13.- Kehr J D, Heukelbach J, Mehlhorn H, Feldmeier H. Morbidity assessment in sand flea disease (tungiasis). Parasitol Res 2007; 100: 413-21.

14.- Heukelbach J, Eisele M, Jackson A, Feldmeier H. Topical treatment of tungiasis: a randomized, controlled trial. Ann Trop Med Parasitol 2003; 97: 743-9.

15.- Heukelbach J, Franck S, Feldmeier H. Therapy of tungiasis: a double-blinded randomized controlled trial with oral ivermectin. Mem Instit Oswaldo Cruz 2004; 99: 873-6.

16.- Feldmeier H, Heukelbach J, Eisele M, Sousa A Q, Barbosa L M, Carvalho C B. Bacterial superinfection in human tungiasis. Trop Med Int Health 2002; 7: 559-64. 